\title{
RANCANGAN PENGEMBANGAN PRODUK BONCENGAN SEPEDA MOTOR UNTUK ANAK DENGAN PENDEKATAN ERGONOMI
}

\author{
Khalid Walidi ${ }^{1)}$ dan Yunia Dwie Nurcahyanie ${ }^{2)}$ \\ 1) 2) Program Studi Teknik Industri; Fakultas Teknologi Industri \\ Universitas PGRI Adi Buana Surabaya \\ Email: khalidelmessayya@gmail.com
}

\begin{abstract}
Abstrak
Penelitian bertujuan untuk memperoleh prototype boncengan sepeda motor untuk anak usia 6-7 tahun dengan menggunakan pendekatan ergonomi yang lebih nyaman. Teknik pengumpulan data yang digunakan dalam penelitian ini adalah kuesioner (angket) dan pengukuran antropometri. Teknik analisis yang digunakan dalam penelitian ini adalah uji kenormalan data, uji kecukupan data, dan uji statistic paired sample t-test. Hasil penelitian dari uji kenormalan data dinyatakan normal, uji kecukupan data menunjukkan bahwa data tersebut dinyatakan cukup. Uji statistic paired sample t-test, nilai konfidensi interval: $-1,22508<\mu_{\text {sebelum }}-\mu_{\text {sesudah }}<-0,88159$. Dengan menggunakan nilai $t$ hit 12,544, jika nilai ini diberi harga mutlak $=12,544$ maka t tabel $=2,262$. Karena $t$ hit $>t$ tabel maka disimpulkan $H_{0}$ ditolak, artinya ada perbedaan tingkat kenyamanan dan keergonomisan secara statistik dari pengguna sebelum dan sesudah adanya pengembangan produk boncengan. Hal ini bisa dilihat dari signifikan 0,000 (<0,05). Dapat disimpulkan bahwa hipotesis $H_{0}$ yang menyatakan tidak ada perbedaan rata-rata kenyamanan sebelum dan sesudah adanya pengembangan ditolak. Pengembangan produk boncengan dari penelitian sebelumnya memberikan dampak perbedaan antara rata-rata kenyamanan dan keergonomisan sebelum dan sesudah adanya pengembangan pada produk boncengan sepeda motor anak dengan peningkatan hingga 37\% dari sebelum pengembangan.
\end{abstract}

Kata kunci; Rancangan Pengembangan, Produk, Boncengan Motor Untuk Anak, Ergonomi

\begin{abstract}
The purpose of this research is the $63^{\text {rd }}$ rides prototype motorcycles for children aged 6-7 years with the use of a more comfortable ergonomics approach. Data collection techniques used in this study was a detailed questionnaire (the now), and anthropometry measurements. Analytical techniques used in this research is to test data, the average adequacy of data, statistics and test paired sample t-test. From test the data seen that data is declared normal. Research results from the test of the adequacy of the data adequacy the stated simply. Test statistics for paired samples t-test, it can be seen from the significant $0.000(<0.05)$. It can be concluded that the hypothesis $H_{0}$ stating there is no difference in average comfort before and after the existence of the development was rejected. That turned out to be boncengan of product development research before giving the impact difference between average comfort and ergonomic before and after the existence of the development on the product ride kid motor cycle with increased to $37 \%$ from before the development.
\end{abstract}

Keywords; Product Development, Ride along Motorcycle for Kids, Design Ergonomics

\section{PENDAHULUAN}

Kecelakaan kendaraan di jalan raya didominasi oleh pengendara sepeda motor yaitu sebesar 70\%. Menurut data WHO tahun 2011 menyebutkan, sebanyak $67 \%$ korban kecelakaan lalu lintas berada pada usia produktif yaitu 22-40 tahun. Terdapat sekitar 400.000 korban di bawah usia 25 tahun yang meninggal di jalan raya, dengan rata-rata angka kematian 1.000 anak-anak dan remaja setiap harinya. Bahkan, kecelakaan lalu lintas menjadi penyebab utama kematian anak-anak di dunia, dengan rentang usia 10-24 tahun. Berdasarkan Outlook tahun 2013, Transportasi Indonesia, terdapat empat faktor penyebab kecelakaan, yakni kondisi sarana, prasarana transportasi, faktor manusia dan alam. Faktor utama penyebab tingginya angka kecelakaan lalu lintas pada sepeda motor adalah karena sepeda motor tidak hanya digunakan untuk membonceng orang dewasa saja tetapi juga 
digunakan untuk membonceng anak-anak. Untuk mengatasi masalah tersebut, dipasaran sudah ada boncengan anak yang dinamakan helmiat. Boncengan ini terdiri dari rangka stainless steel, sandaran punggung menggunakan busa dengan bahan pelapis anti air, dan sabuk pengaman di depan sandaran. Akan tetapi masih ada kekurangan pada produk helmiat ini yang dilihat dari segi kenyamanan anak. Dalam pengembangan produk selalu diperhatikan kebutuhan konsumen sebagai pengguna (King, 1995). Oleh karena itu, perlu dilakukan pengembangan produk helmiat dengan memperhatikan faktor estetika produk yaitu enak, nyaman, aman, sehat, efektif dan efisien (Otto, 2001). Hal ini dimaksudkan agar dapat mengurangi salah satunya ketidaknyamanan anak pada saat dibonceng sepeda motor. Menurut Simamora (2000), pengertian pengembangan produk adalah proses pencarian gagasan untuk barang atau jasa baru dan mengkonversikannya kedalam tambahan lini produk yang berhasil secara komersial, didasarkan pada asumsi bahwa para pelanggan menginginkan unsur-unsur baru yang akan membantu mencapai tujuan perusahaan (Bhattacharyya dan Rahman, 2004). Menurut Sritomo (2003), antropometri adalah suatu ilmu yang secara khusus mempelajari tentang pengukuran tubuh manusia yang berfungsi untuk merumuskan perbedaan-perbedaan ukuran pada tiap individu atau kelompok. Maka diperlukan bagaimana merancang dalam mengembangkan produk boncengan sepeda motor ergonomi untuk anak usia 6-7 tahun dalam meningkatkan kenyamanan, keamanan, keefektifan dan keefisienan pada pengguna. Pengembangan produk dibutuhkan untuk penghematan dan efisiensi produksi dan pasca produksi (Clausing, 1995). Menurut Grieves (2005), manajemen produk baru diperlukan untuk keberlanjutan dan kesesuaian produk dengan kebutuhan masyarakat terkini.

\section{METODOLOGI}

\section{Variabel penelitian}

Variabel yang digunakan dalam penelitian ini adalah :

1. Variabel Bebas (Variabel X)

Variabel bebas atau variabel independen yaitu variabel yang mempengaruhi variasi perubahan nilai variabel terikat. Variabel bebas dalam penelitian ini adalah Boncengan Sepeda Motor.

2. Variabel Terikat (Variabel Y)

Variabel terikat atau variabel dependen adalah variabel yang nilainya tergantung dari variasi perubahan variabel bebas. Variabel terikat yang diteliti adalah Nilai Antropometri.

Dari variabel diatas dapat dijelaskan beberapa sub variabel dilihat pada Tabel 1 .

Tabel 1. Definisi Operasional Variabel

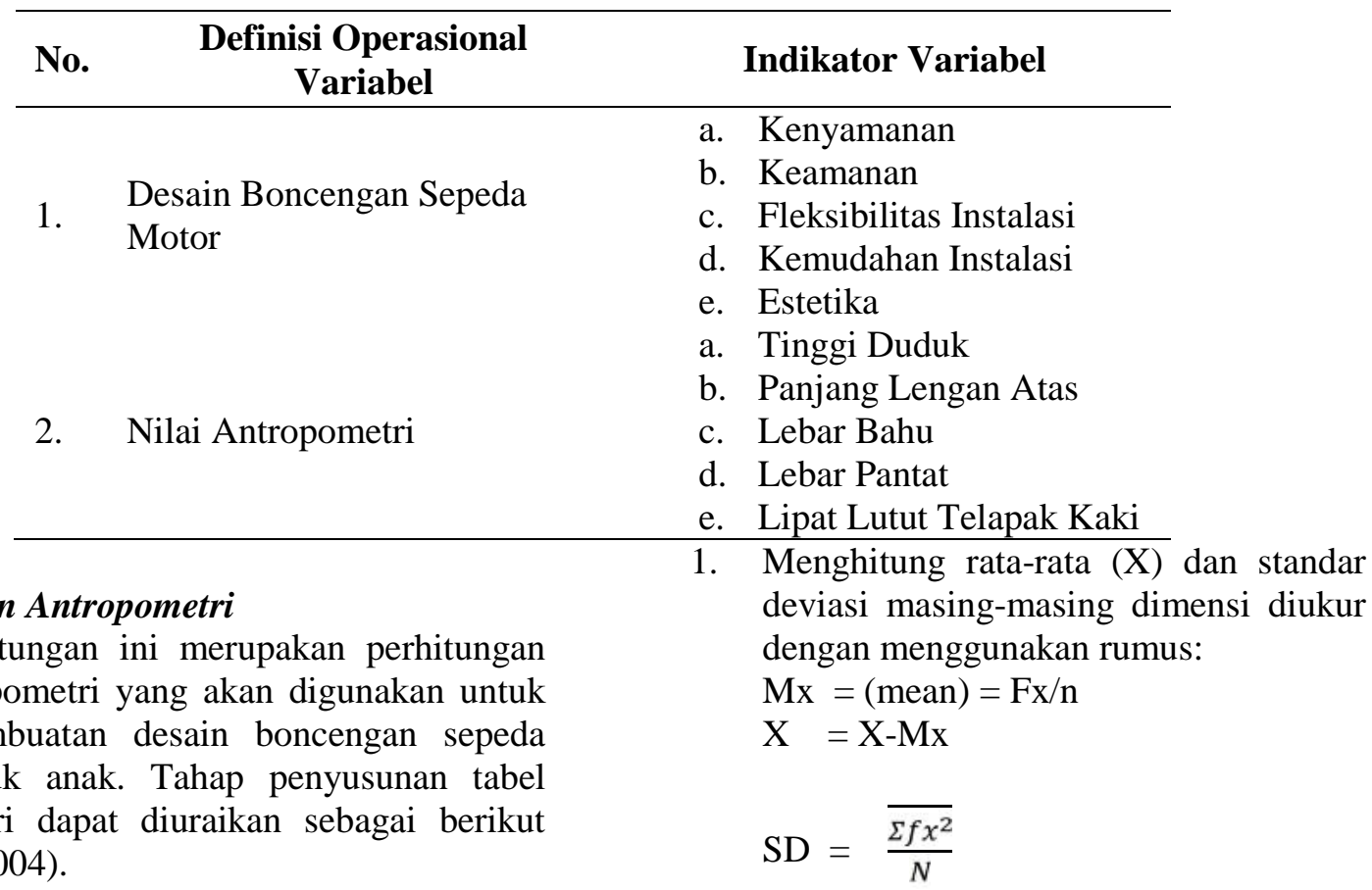

\section{Perhitungan Antropometri}

Perhitungan ini merupakan perhitungan jenis antropometri yang akan digunakan untuk proses pembuatan desain boncengan sepeda motor untuk anak. Tahap penyusunan tabel antropometri dapat diuraikan sebagai berikut (Santoso, 2004). a. Kenyamanan

e. Estetika

a. Tinggi Duduk

b. Panjang Lengan Atas

c. Lebar Bahu

d. Lebar Pantat

e. Lipat Lutut Telapak Kaki deviasi masing-masing dimensi diukur dengan menggunakan rumus:

$\mathrm{Mx}=($ mean $)=\mathrm{Fx} / \mathrm{n}$

$\mathrm{SD}=\overline{\frac{\Sigma f x^{2}}{N}}$ 
$\Sigma=$ Jumlah keseluruhan

$\mathrm{SD}=$ Standart deviasi

$\Sigma \mathrm{fx}^{2}=$ Jumlah perkalian antar frekuensi masing-masing skor, dengan deviasi skor yang dikuadratkan.

$$
\mathrm{N}=\text { Number of cases }
$$

2. Dalam antropometri percentile ukuran 95 $5^{\text {th }}$ menunjukkan ukuran "terbesar" dan percentile $5^{\text {th }}$ menunjukkan ukuran

yang pada umumnya digunakan yaitu $5^{\text {th }}$, dan $95^{\text {th }}$ dengan rumus:

1. Percentile 5:

$$
5 \text { th }=\overline{\mathrm{X}}-1,645 . \mathrm{SD}
$$

2. Percentile 95:

$$
\text { 95th }=\overline{\mathrm{X}}+1,645 . \mathrm{SD}
$$

Tabel 2 Pemakaian Umum Nilai-Nilai Percentile

\begin{tabular}{cc}
\hline Percentile & Perhitungan \\
\hline 1-th & $-2.325 \sigma \mathrm{X}$ \\
2,5-th & $-1.96 \sigma \mathrm{X}$ \\
5 -th & $-1.645 \sigma \mathrm{X}$ \\
10-th & $-1.28 \sigma \mathrm{X}$ \\
$50-$ th & \\
90-th & $+1.28 \sigma \mathrm{X}$ \\
95-th & $+1.645 \sigma \mathrm{X}$ \\
97,5-th & $+1.96 \sigma \mathrm{X}$ \\
99-th & $-2.325 \sigma \mathrm{X}$ \\
\hline
\end{tabular}

\section{Uji Kecukupan}

Uji kecukupan data untuk mengetahui apakah data yang diperoleh sudah mencukupi untuk diolah dengan menggunakan tingkat kepercayaan $95 \%$ dan tingkat ketelitian $5 \%$.

$$
\mathbf{N}^{\prime}=\frac{\frac{k}{s} \overline{N \sum x^{2}-{\overline{(\Sigma x)^{2}}}^{2}}}{\sum x}
$$

Dengan:

$\mathrm{k}$ : Tingkat keyakinan

$\mathrm{k}: 95 \%=2$

\section{Uji Paired Sample T-Test}

Analisis dengan melibatkan dua pengukuran pada subjek yang sama terhadap suatu pengaruh

\section{HASIL DAN PEMBAHASAN}

\section{Hasil Perhitungan Antropometri}

Perhitungan antropometri dilakukan dengan perhitungan total, mean,standar deviasi $\mathrm{s}:$ Derajat ketelitian

$\mathrm{N}$ : Jumlah data pengamatan

$\mathrm{N}^{\prime}:$ Jumlah data teoritis

\section{Uji Kenormalan}

Pengujian yang dilakukan untuk mengetahui apakah data hasil pengukuran berdistribusi normal atau tidak, sehingga nantinya memudahkan dalam pengolahan datanya dan proses pengerjaan uji kenormalan data.

atau perlakuan tertentu (Trihendradi, 2010). Sampel yang diambil pada penelitian ini sebanyak 30 anak dari usia 6-7 tahun di SD Negeri Lalangon 1 dari 100 anak (Populasi). dan persentile dapat dilihat pada Tabel 3. Tabel 3 menunjukkan bahwa persentil $95^{\text {th }}$ tertinggi adalah $60,2 \mathrm{~cm}$ pada tinggi duduk dan terendah $22 \mathrm{~cm}$ pada lebar pantat. 


\begin{tabular}{clcccc}
\hline \multicolumn{4}{c}{ Tabel 3. Hasil Perhitungan Antropometri } \\
\hline \multirow{2}{*}{ No. } & $\begin{array}{c}\text { Jenis } \\
\text { antropometri }\end{array}$ & $\begin{array}{c}\text { Rata-rata } \\
(\mathbf{c m})\end{array}$ & SD & \multicolumn{2}{c}{ Percentile } \\
\cline { 5 - 6 } & Tinggi duduk & 55,4 & 2,87 & 50,6 & 60,2 \\
2 & Panjang lengan & 21,33 & 1,92 & 18,2 & 24,4 \\
& atas & & & & \\
3 & Lebar bahu & 30,7 & 1,87 & 27,6 & 33,8 \\
4 & Lebar pantat & 25,1 & 1,92 & 22,0 & 28,2 \\
5 & Lipat lutut telapak & 31,3 & 2,40 & 27,4 & 35,2 \\
& kaki & & & & \\
\hline
\end{tabular}

\section{Hasil Uji Kecukupan}

Hasil uji kecukupan data tiap dimensi antropometri dapat dilihat pada Tabel 4. Hasil perhitungan uji kecukupan data menyatakan bahwa $\mathrm{N}^{\prime} \leq \mathrm{N}$, sehingga uji kecukupan data tersebut dinyatakan cukup.

Tabel 4. Hasil Kecukupan Data

\begin{tabular}{ccccc}
\hline No & $\begin{array}{c}\text { Dimensi } \\
\text { Tubuh }\end{array}$ & N & N' & Keterangan \\
\hline 1 & TD & 30 & 4,2967523 & Cukup \\
2 & PLA & 30 & 3,5380858 & Cukup \\
3 & LB & 30 & 2,9020961 & Cukup \\
4 & LP & 30 & 9,3712797 & Cukup \\
5 & LLTK & 30 & 9,3798378 & Cukup \\
\hline
\end{tabular}

Keterangan :

TD : Tinggi Duduk

PLA : Panjang Lengan Atas

LB : Lebar Bahu

LP : Lebar Pantat

LLTK : Lipat Lutut telapak Kaki

\section{Hasil Uji Kenormalan}

Uji kenormalan data dimensi tubuh dilakukan dengan menggunakan One-Sample Kolmogorov-Smirnov Test. Dasar pengambilan uji kenormalan data dilihat dari nilai Sig $>0,05$, yaitu (TD) 0,442, (PLA) 0,235 , (LB) 0,779, (LP) 0,839 , (LLTK) 0,542 sehingga data tersebut dinyatakan normal yang dapat dilihat pada Tabel 5.

\section{Hasil Paired Sample T-test}

Hasil penelitian ini sebelum dan sesudah adanya pengembangan menggunakan uji Paired Sampel T-Test dapat dilihat pada Tabel 5.

Tabel 5. Hasil Uji Paires Sample T-Test

Paired Samples Statistics

\begin{tabular}{llcccc}
\hline & & Mean & $\mathrm{N}$ & Std. Deviation & $\begin{array}{c}\text { Std. Error } \\
\text { Mean }\end{array}$ \\
\hline Pair 1 & Sebelum & 2.7467 & 30 & .37484 & .06844 \\
& sesudah & 3.8000 & 30 & .38056 & .06948 \\
\hline
\end{tabular}

Paired Samples Correlations

\begin{tabular}{llccc}
\hline & & $\mathrm{N}$ & Correlation & Sig. \\
\hline Pair 1 & sebelum \& sesudah & 30 & .259 & .168 \\
\hline
\end{tabular}


Paired Samples Test

\section{Paired Differences}

\begin{tabular}{|c|c|c|c|c|c|c|c|c|c|}
\hline & & & & Paired Differ & ces & & & & \\
\hline & & & & Std. Error & $\begin{array}{l}5 \% \text { Confiden } \\
\text { of the Dif }\end{array}$ & $\begin{array}{l}\text { Interval } \\
\text { rence }\end{array}$ & & & Sig. (2- \\
\hline & & Mean & Deviation & Mean & Lower & Upper & $\mathrm{t}$ & df & tailed) \\
\hline Pair 1 & $\begin{array}{l}\text { sebelum - } \\
\text { sesudah }\end{array}$ & -1.05333 & .45994 & .08397 & -1.22508 & -.88159 & -12.544 & 29 & .000 \\
\hline
\end{tabular}

Nilai konfidensi interval: $-1,22508<$ $\mu_{\text {sebelum }}-\mu_{\text {sesudah }}<-0,88159$. Dengan menggunakan nilai t hit $-12,544$, jika nilai ini diberi harga mutlak $=12,544$ maka $\mathrm{t}$ tabel $=$ 2,262 . Karena $t$ hit $>t$ tabel maka disimpulkan Ho ditolak, artinya ada perbedaan tingkat kenyamanan dan keergonomisan secara statistic dari pengguna sebelum dan sesudah adanya pengembangan produk boncengan. Hal ini bisa dilihat dari signifikan $0,000 \quad(<0,05)$, yang artinya bahwa hipotesis Ho yang menyatakan tidak ada perbedaan rata-rata kenyamanan sebelum dan sesudah adanya pengembangan ditolak. Dengan kata lain bahwa ternyata

\section{KESIMPULAN}

Berdasarkan hasil analisis jenis kenyamanan pada poduk boncengan sepeda motor anak dapat diketahui bahwa tingkat kenyamanan responden mengalami peningkatan yang signifikan setelah menggunakan re-desain boncengan sepeda motor untuk anak dengan menggunakan ukuran antropometri tubuh dalam pembuatan boncengan ergonomis sepeda motor untuk anak meliputi tinggi duduk, panjang lengan atas, lebar bahu, lebar pantat, dan lipat lutut telapak kaki. Pembuatan alat yang diperuntukkan pada manusia dan diukur dengan antropometri tubuh maka hasilnya akan sesuai, dan pada akhirnya pengguna alat akan merasa nyaman untuk menggunakan alat tersebut. Dan menurut hasil analisis Paired Sample T-Test terhadap boncengan sepeda motor untuk anak diketahui bahwa terdapat peningkatan kenyamanan sebelum dan sesudah pengembangan boncengan sepeda motor. Berdasarkan hasil uji statistik untuk tingkat kenyamanan, keamanan, kemudahan instalasi, fleksibilitas instalasi, dan estetika mengalami peningkatan dari rancangan boncengan sepeda motor pada penelitian sebelumnya. Seperti pengembangan produk boncengan dari penelitian sebelumnya memberikan dampak perbedaan antara rata-rata kenyamanan dan keergonomisan sebelum dan sesudah.

\section{Interpretasi}

Hasil pengembangan boncengan sepeda motor untuk anak ini mengalami peningkatan kenyamanan pada penggunanya, dapat dilihat hasil $\mathrm{t}$ hitung lebih besar daripada $\mathrm{t}$ tabel. Sehingga pengembangan produk mengalami tingkat kenyamanan. Responden mengatakan bahwa produk boncengan anak ini telah memenuhi desain yang ergonomis karena mengalami peningkatan tingkat kenyamanan.

halnya adanya sandaran kepala dengan sistem slide untuk mengatur tinggi rendahnya kepala pemakai, adanya footstep (pijakan kaki), dan tidak merubah atau merusak body pada motor untuk pembuatan plunger seperti halnya rancangan sebelumnya yang cenderung merusak body untuk mendapatkan posisi penempatan boncengan. Sehingga dapat dinyatakan boncengan anak tersebut ergonomis. Dan bagi orang tua agar memperhatikan kenyamanan pada anak disaat membonceng ketika berkendara, bagaimanapun keamanan pada anak menjadi yang utama selain juga harus fokus dan konsentrasi dalam mengemudi. Dalam pembuatan alat agar diperhatikan tingkat kenyamanan dan keamanan bagi penggunanya menggunakan nilai-nilai ergonomis dengan melakukan pengukuran antropometri anggota tubuh penggunanya.

\section{UCAPAN TERIMA KASIH}

Ucapan terima kasih ditujukan kepada Universitas PGRI Adi Buana (UNIPA) Surabaya sebagai tempat penelitian dan analisis sampel. 


\section{DAFTAR PUSTAKA}

Bhattacharyya, S. K., \& Rahman, Z. (2004). Capturing the customer's voice, the centerpiece of strategy making: A case study in banking. European Business Review, 16(2), 128-138.

Clausing, D. 1994. Total quality development - A step by step guide to world-class concurrent engineering. New York: ASME Press.

Grieves, M. (2005). Product lifecycle management. Driving the next generation of lean thinking. McGraw-Hill.,

King, B. (1995). Designing products and services that customer wants. Productivity Press.

Otto, K., Wood, K., (2001), Product Design- Technical in Reverse Engineering And New Product Development, London: Prentice Hall.

Santoso, G. (2004), Ergonomi Manusia, Peralatan dan Lingkungan. Prestasi Pustaka. Jakarta.

Simamora, H. (2000), Manajemen Pemasaran International, Jilid Kedua. Salemba Empat. Jakarta.

Trihendradi, C. (2005), SPSS 13 Analisis Data Statistik. Andi. Yogyakarta.

Wignjosoebroto, S. (2003), Ergonomi Studi Gerak dan Waktu : Teknik Analisis untuk Peningkatan Produktivitas Kerja. PT. Guna Widya. Jakarta. 